\title{
A Case Study of Dwellings' Changes in Ba Piao Village and Baka Laozhai Village of the Jinuo Nationality: 1980-2020
}

\author{
Qin $\mathrm{Li}^{1}$ Jing Guo ${ }^{1}$ Weibing $\mathrm{Li}^{1, *}$ \\ ${ }^{1}$ College of Design, Yunnan Arts University, Kunming, Yunnan 650500, China \\ *Corresponding author. Email: 352380477@qq.com
}

\begin{abstract}
Since the reform and opening up, the Jinuo nationality has developed into a rather typical "Jinuo model" — low starting point and high speed [1]. The dwellings of the Jinuo nationality are also undergoing changes, resulting in changes from bamboo huts with thatched roofs to stilt wooden houses with filament tiles, asbestos tiles, color steel tiles, blue tile roofs, and brick-concrete structures. These changes reflect the changes in the production and lifestyle of the Jinuo people, the economic development, and the integration of the regional cultures of the people of all ethnic groups.
\end{abstract}

Keywords: Jinuo model, Rural revitalization, Dwellings' changes.

\section{INTRODUCTION}

In 2017, China implemented the strategy of rural revitalization and put forward the requirements of "prosperous industry, livable ecology, civilized rural customs, effective governance, and prosperous life". "Straight-through nation" is a special concept used under specific historical conditions in China. Solving the development problem of "straight-through nation" is an important content of the country's rural revitalization, border governance, and national development. The Jinuo nationality is the "straightthrough nation" finally confirmed in China, with a total population of about $23,000^{1}$, which is unique to Xishuangbanna Prefecture, Yunnan Province.

Baka Laozhai belongs to the Baka Village Committee of Jinuo Township. It is 31 kilometers away from the township government. The village is built according to the topography and has a belt-

*Project: The Scientific Research Fund Project of the Education Department of Yunnan Province "Research on the Evolution and Renewal Design of the Houses of the Jinuo Nationality in Yunnan from the Perspective of Rural Revitalization" (2021Y574).

1. Statistics from the sixth national population census in 2010 shaped vein layout along the main road ("Figure $1 ")$. The village buildings and the surrounding natural environment form a coordinated overall space. The surrounding natural environment is good, with shady trees, beautiful environment, and harmonious coexistence with the village. The main public buildings and public spaces in the village are the village committee, activity room and basketball court at the entrance of the village. There is also a tea warehouse and two shops. There are 65 households with a total of 283 people in Baka Old Village (2017 data), and it is listed as one of the villages with ethnic minority characteristics in China. 


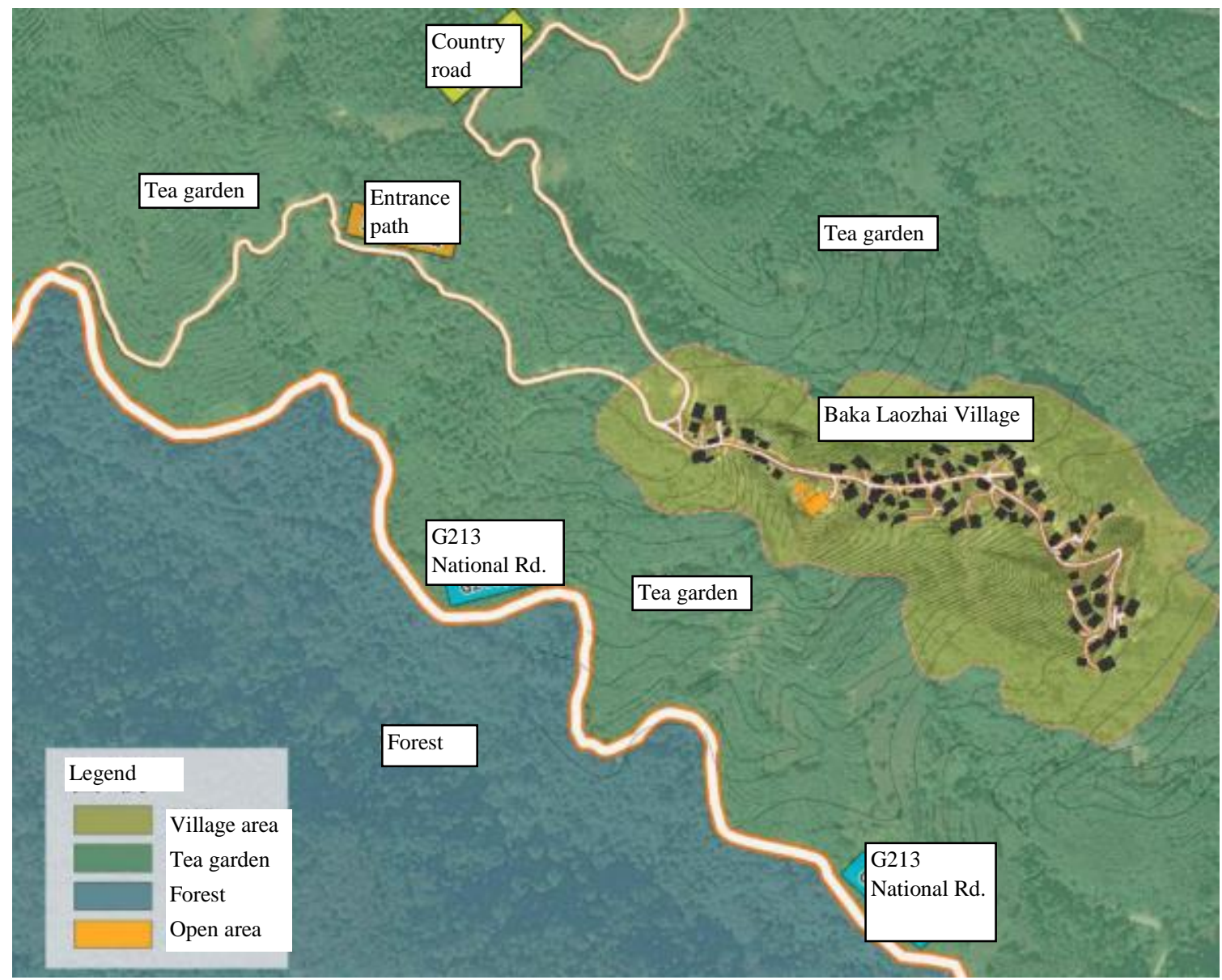

Figure 1 General plan of Baka Laozhai. [2]

a Source: Tian Yunxi. Research on the Landscape Pattern Characteristics of Traditional Villages in Jinuo Mountain in Jinghong Section of Yunnan-Tibet Ancient Tea Horse Road [D]. Southwest Forestry University, 2018

Ba Piao Village is affiliated to the Xinsitu Village Committee of Jinuo Township and is located in the north of Jinuo Township, $1 \mathrm{~km}$ away from the township government. There are 60 rural households with a total of 278 people (2013 data). In 2013, it was listed as a "One Thing, One Discussion" Financial Award and Supplement Demonstration Village by the Xishuangbanna Prefecture Finance Bureau and Jinghong City Finance Bureau, and comprehensive renovation of the facilities in the village was carried out. The original Ba Piao Village is in the mountains and the traffic was very inconvenient. In 2002, the extreme heavy rain caused a landslide in old $\mathrm{Ba}$ Piao Village. The houses of farmers in the whole village were damaged to varying degrees, posing great safety risks and unable to live. In December 2004, 56 households in the village completed the relocation of the whole village. All houses in new Ba Piao Village are allocated by the government. The foundation is divided into two types: $12 * 13 \mathrm{M}$ and $13 * 14 \mathrm{M}$. The villagers draw lots to determine the homestead and build their own houses. Therefore, the basic construction situation of $\mathrm{Ba}$ Piao Village is unified, forming a good village appearance. ("Figure 2").

Jinuo Township has 7 village committees and 46 natural villages. Ba Piao Village is the most well-preserved stockade of the original village in the Jinuo relocation plan. Both filament tiles and asbestos tiles are used to build the village; Baka Laozhai was planned as a small blue tile roof, but the villagers used the method of combining color steel tiles and small blue tiles in the process of selfconstruction. The changes in the dwellings of the two villages are a reflection of the social changes of the Jinuo people in contemporary times, and a model for studying the social development, cultural changes and rural revitalization of the Jinuo people in contemporary times. 


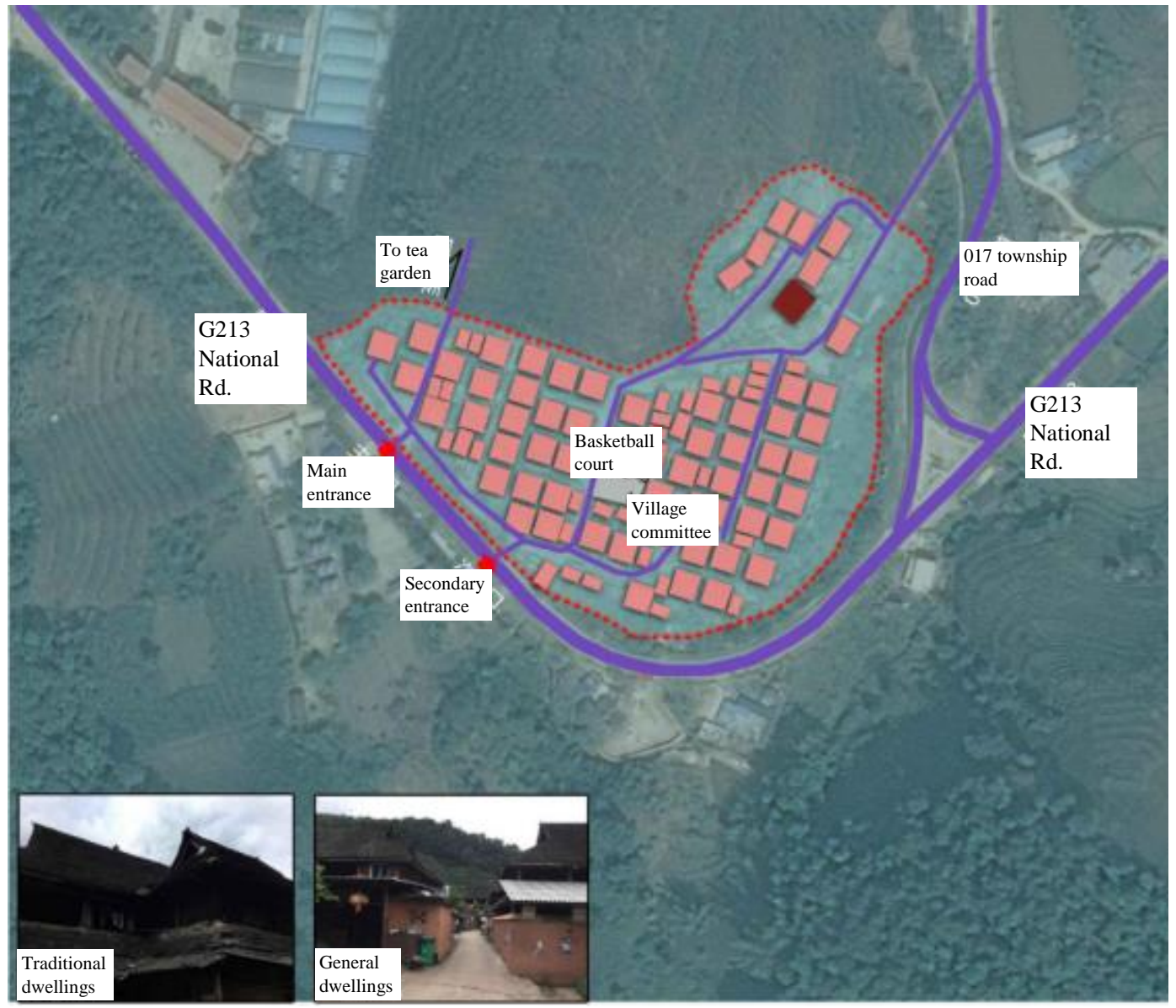

Figure 2 General plan of Ba Piao Village. [2]

a Source: Tian Yunxi. Research on the Landscape Pattern Characteristics of Traditional Villages in Jinuo Mountain in Jinghong Section of Yunnan-Tibet Ancient Tea Horse Road [D]. Southwest Forestry University, 2018.

\section{JINUO THATCHED COTTAGES BEFORE 1980}

The earliest document recorded by the Jinuo tribe is mainly the "General History of Yunnan"2 in the Daoguang period, which records the reason why the Jinuo tribe mainly hunted wild animals for food and three pinches of hair. Regarding the origin of the Jinuo nationality, academic circles have not yet concluded. However, according to the legend of the century, the story of "Amaoyaobei" ${ }^{3}$ and the story about the flood and the marriage of brothers and sisters can reflect the traces of hemorrhagic marriage and the worship of the matriline. According to the route of sending the soul, it proves that the Jinuo people settled in the age of matrilineal blood. In the Keno Mountains [3]. The highest altitude in the territory is 1691.6 meters and

2. Three pinches of hair, namely the black pie... feed on wild animals. Men work hard on farming, women work hard. nationality. the lowest is 550 meters. The average annual rainfall is about 1100 milliliters $^{4}$. It is warm, rainy, and foggy all year round. It is covered by tropical monsoon forests and tropical broad-leaved forests. The unique tropical mountain forest environment bestows the Jinuo people with rich Natural resources. According to historical records, "Records of Ming Taizu Hongwu", "Yuan History", and "Jingtai Yunnan Illustrated Scriptures", it is estimated that the Jinuo people had frequent exchanges with the Dai and Hani people living in the surrounding areas more than 700 years ago.

\subsection{Inheritance and Strengthening of Plane Form}

The earliest Jinuo traditional dwellings used locally grown bamboo as a building material. Later, relatively durable wood gradually replaced bamboo, but the roof was still a straw raft made of

4. The data comes from the internal data of the People's Government of Jinuo Township, Jinghong City in 2018. 
thatch. According to the "Social and Historical Survey of the Dai People", the style of the thatched huts in Jinuo Mountain is similar to that of the Dai people. It is divided into upper and lower floors, with livestock raised on the lower floor and people living on the upper floor. Some dwellings have one staircase, and some have two staircases. Generally, there is a bamboo platform at the entrance of the second floor, which is usually used as a grain terrace, and as a delivery room when women give birth ("Figure 3"). When people enter the door, they will see an open hall with a pillar in the middle, a firepit next to it, and many separate bedrooms on both sides of the house [4]. In some villages, the "long house", the largest family cohabitation model for ethnic minorities in southern China, once existed. The largest long house is the long house of the Acerao family, which once had 28 households with 125 people [5] ("Figure 4").
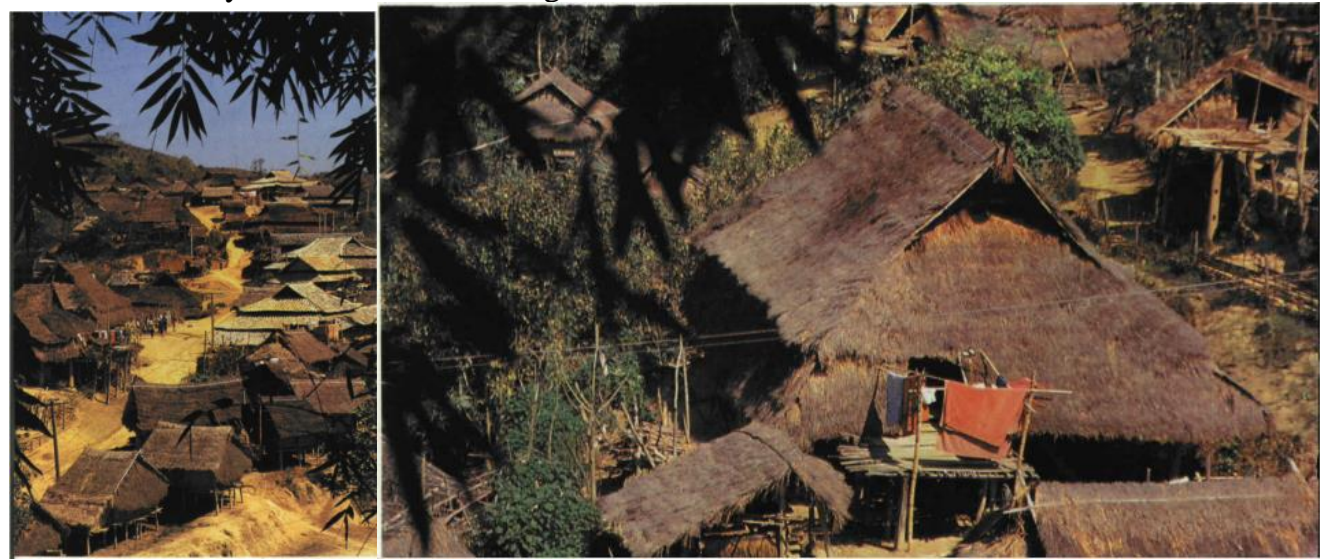

Figure 3 Traditional Jinuo village. [6]

a Selected from Wang Cuilan and Chen Moude. The sequel of Yunnan Dwellings [M]. Beijing: China Building Industry Press, 1993.

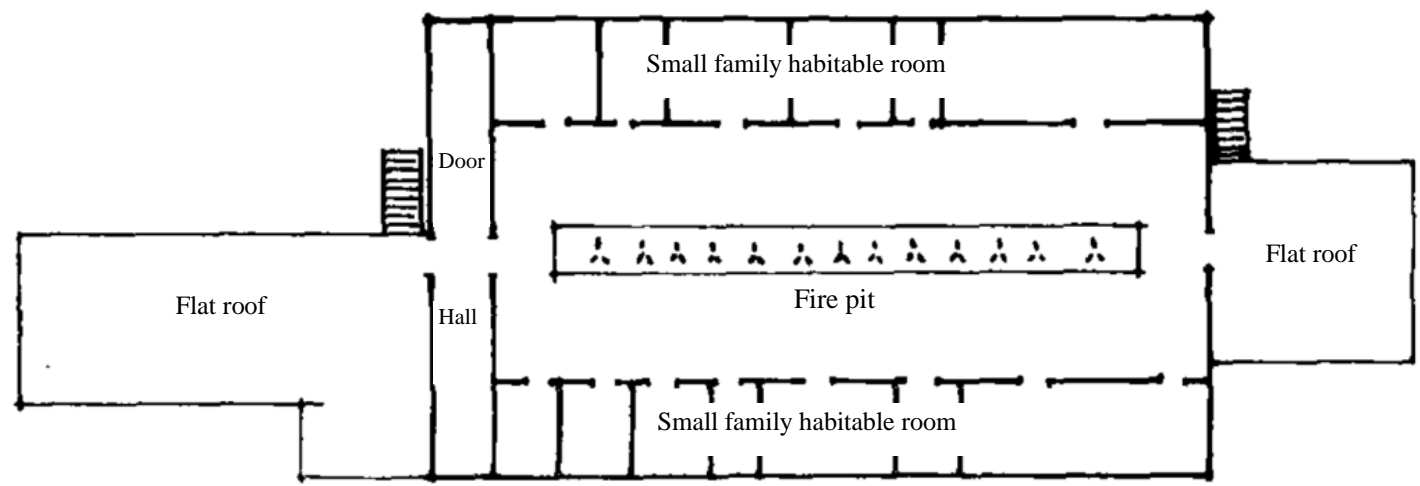

Figure 4 A plan view of the long house of the Yanuozhai Acerao family of the Jinuo nationality. [6]

Selected from Wang Cuilan and Chen Moude. The sequel of Yunnan Dwellings [M]. Beijing: China Building Industry Press, 1993.

The living style of the Jinuo people has undergone changes from caves, shacks, stilt bamboo buildings, and civil-timbered houses. In the era of Sijie Zhuomi, the Jino people lived by gathering and hunting, using caves, tree caves, and shacks as shelters from wind and rain. After they settled down at Jiezhuo Mountain, they gradually changed from shacks to stilt bamboo buildings. The thatched huts of the Jinuo people inherit and strengthen the characteristics of the dwellings of the Jinuo and Dai peoples. Whether it is a single building or a settlement group, it reflects the core cohesion of the paternal clan society.

\subsection{Optimization of Structural System}

The five god pillars are particularly important in the construction of traditional dwellings of the Jinuo nationality (see "Figure 5"). The first column is called "Mai Niu Ke", that is, the father column. It is the family deity established during the death and rebirth process of the head of the family, giving the 
owner the position of God, commanding hunting things.

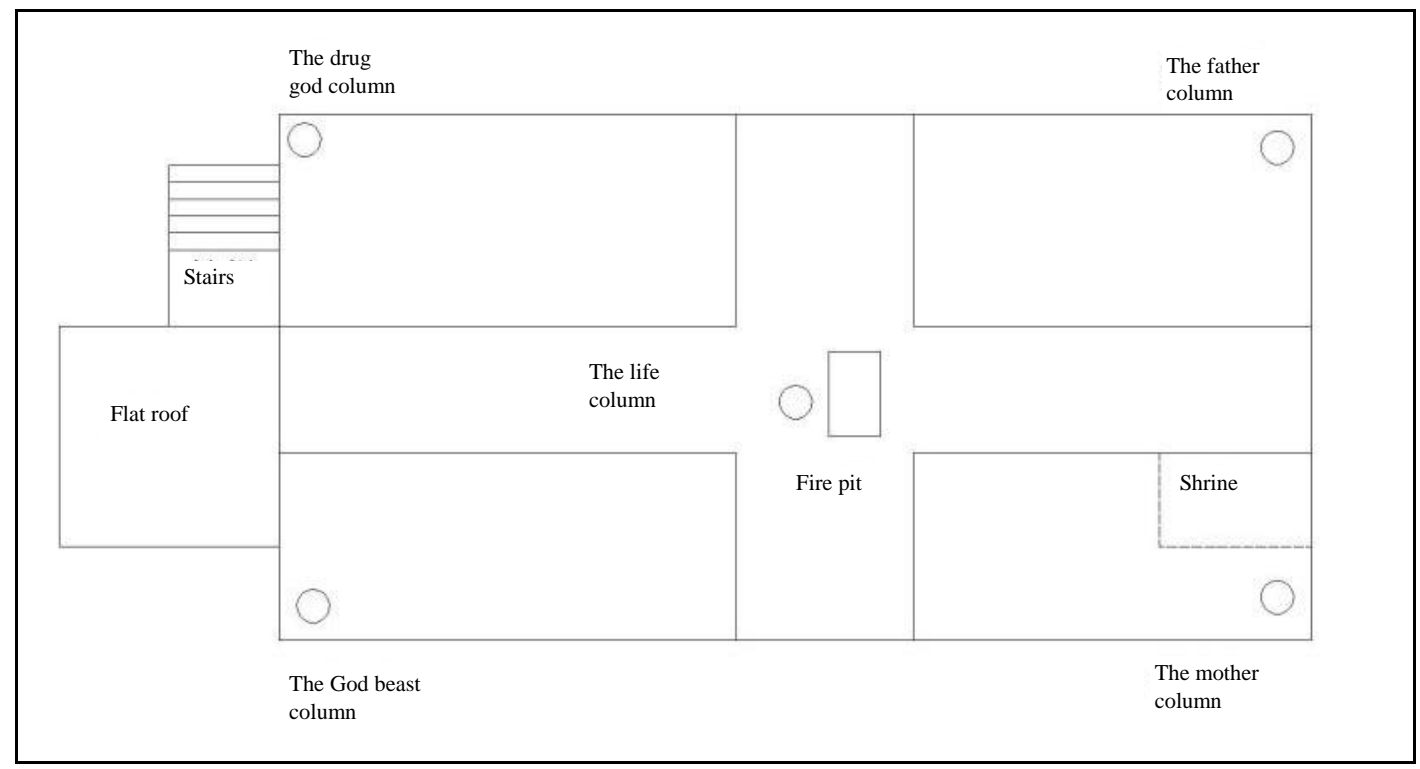

Figure 5 Schematic diagram of the five god pillars in the traditional dwellings of Jinuo nationality. (Self-drawn by the author)

The second pillar is called "Su Tu Ke", that is, the drum god column. Its god is the cowhide wooden drum hung in the Zhuoba drum room. The room under this column is specially set up for drums, and no other objects can be placed; nonZhuoba people have a vacant seat in this room. The sacredness of the Jinuo drum is that it can only be struck once during the New Year, but this national drum carnival ceremony has the following three meanings: one is the boundary between death and regeneration of villagers' life etiquette; one is the boundary between life and death in the annual cycle of slash-and-burn mountain agriculture; and the third is the boundary between the mission of sending off the old and welcoming the new by the first priest of the cottage, Zhuoba. The third column is called "Bu Na Ke", which is the mother column. The place of the shrine is also here, this column belongs to the corresponding blacksmith, priest and wizard. The fourth pillar is called "Su Ke", that is, the God beast column. Below this column is the animal room, and a bamboo bed is placed against the inner wall in the room. This is the place for sacrifice after defeating the beast. On the beams of this column are the skulls of red deer and bison. People regard this as a treasure, which is also the position of God. The traditional belief is that the beast god is a female, and a series of sacrificial rituals are performed after hunting the beast. The protagonist is the hunter who hits the beast; therefore, this house is also a place for adult men to perform divine activities. No other objects were placed under this pillar or in the room. The woman did not participate in the activities here, nor did the room clean, but the man cleaned it. The hunters must leave a memorial for each prey, or horns, or claws, or skulls, or feathers, decorated inside and outside the house. The large hunted prey will also be collected and stored in the beast room together with "Chico" and "Cuckoo". It will no longer be used, and it is only for worship and pray for the next hunting in the "same room". The skeletons of the large hunted game will be collected together with "Chico" and "Cuckoo" and stored in the house of the beast god, which will not be used any more and will only be used for sacrifice and next hunting prayer [7]. The fifth pillar is called "Keku Lao", which means the fall of life, that is, the life column. These five pillars were optimized and improved in later residential houses. Before 1800, the thatched houses on Jinuo Mountain mainly adopted the beam-column mixed load-bearing structure method, which clearly expresses the influence of the Dai's stilt architecture. The interior adopts a double-row column net layout, and eliminates the center column to effectively use and improve the space; secondly, the new frame method is converted to a combination of beams and columns, and a larger space is formed by manufacturing smaller components. These changes were obtained through learning from other ethnic groups, but they were eventually integrated into the traditional dwellings 
of the local Jinuo tribe, and an independent and complete system was established. ("Figure 6")

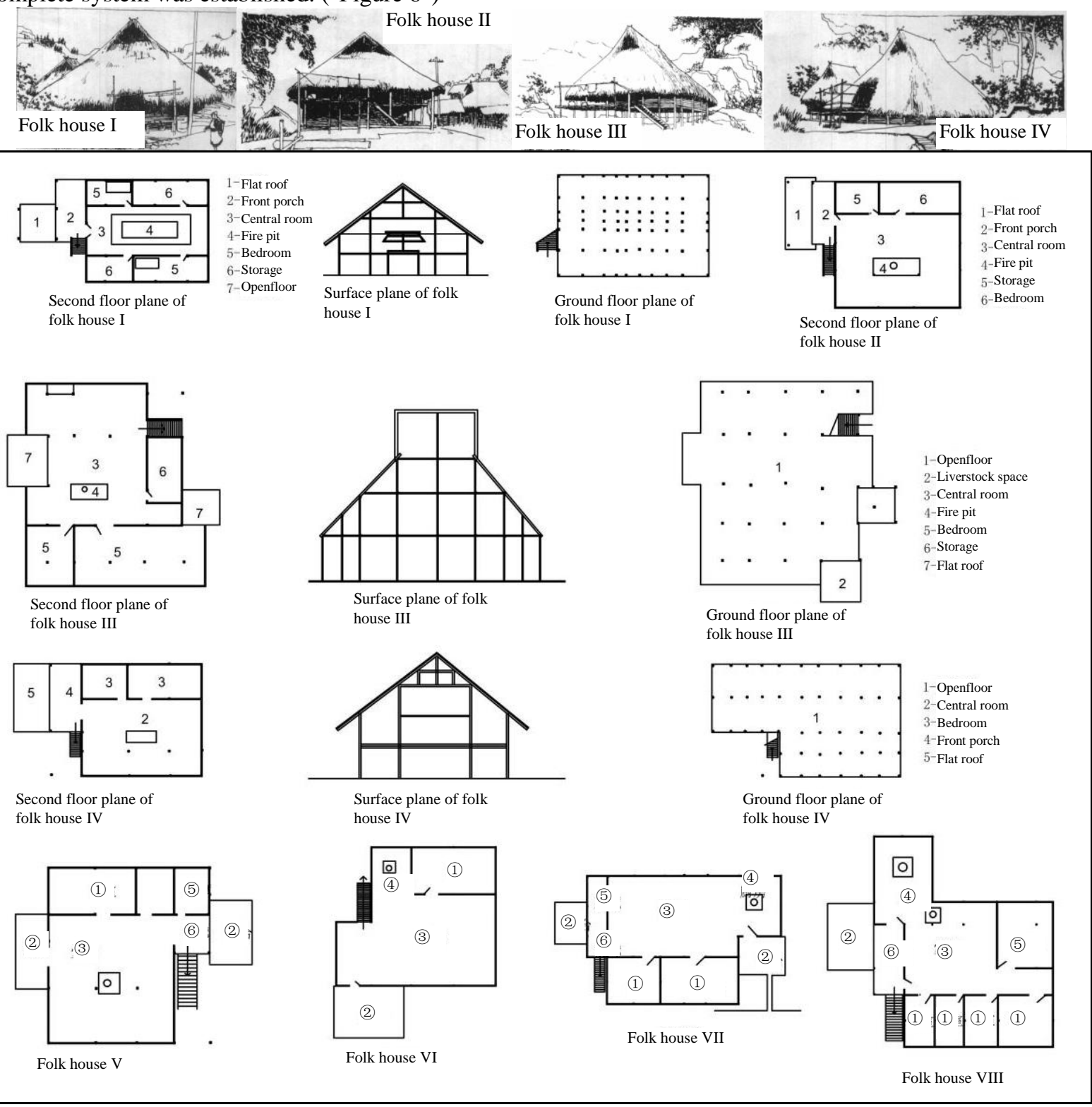

Figure 6 Traditional dwellings of Jinuo nationality. [6]

a Selected from and repainted by Wang Cuilan and Chen Moude. The sequel of Yunnan Dwellings [M]. Beijing: China Building Industry Press, 1993. b (1) - Bedroom; (2) - Flat roof; (3) - Central room; (4) - Kitchen; (5) - Storage; (6) - Front porch.

\section{1980-2000: THE REVOLUTION OF TILED HOUSES}

Around the end of the 20th century, asbestos tile began to enter the Jinuo Mountain as a new type of roofing material. The traditional thatched roof needs to be renovated once every few years, which requires a lot of overhaul and maintenance, and is flammable, which poses great safety risks. Asbestos tiles have the characteristics of light weight, low cost, moisture and corrosion resistance, low temperature resistance, etc., especially good waterproof performance and easy installation. It is an inevitable choice to choose asbestos tiles to replace thatched roofs.

In 1984, the last Jinuo long room disappeared, and the long room culture also disappeared. In the mid-1980s, foreign craftsmen built Han-style brickwood structure bungalows in individual villages, which quickly aroused the interest of the Jinuo 
people, and they followed suit, and combined with the Jinuo folk houses to create stilt wooden roof tiles. By 2003, the villagers of Jinuo Mountain basically lived in tiled houses [5].

The current traditional dwellings in Jinuo Mountain were mostly concentrated in the 1990s, and a small number of brick-concrete dwellings began to be built in the 21 st century. During the period from 1980 to 2000 , new materials were used in a large number of experiments for dwellings' construction. Many foreign craftsmen brought brand-new dwelling skills to Mountain Jino, and the exchange and integration with local craftsmen together created the traditional Jino rdwellings that people still see today. The Zhuoba home in Ba Piao Village was built by the village's craftsmen. In addition to using original construction techniques, it also incorporates new construction methods. The new dwellings under construction use a roof form and a plan layout form completely different from that of the thatched house. When the occupants change the position of the stairs, they also add two plane units to expand the area of the second floor. In the "凹"-shaped plane recess of the house, a floor slab was added to make it neat and coherent, and an asbestos tile roof was added to the new floor slab. The kitchen with brick-concrete bathroom and asbestos tile roof was added on the first floor to increase the durability of the bathroom without destroying the overall coordination. The kitchen was changed to economical and easy-to-replace asbestos tiles ("Figure 7", "Figure 8" and "Figure 9").

The extensive use of asbestos tiles has made a huge change in the appearance of traditional villages. However, asbestos tile is an internationally recognized building material to be eliminated. More importantly, asbestos, as a strong carcinogen, has been explicitly banned in many countries. Because the villagers lack the necessary technical support and knowledge reserves, the negative impact brought about by the new materials can only be passively accepted.

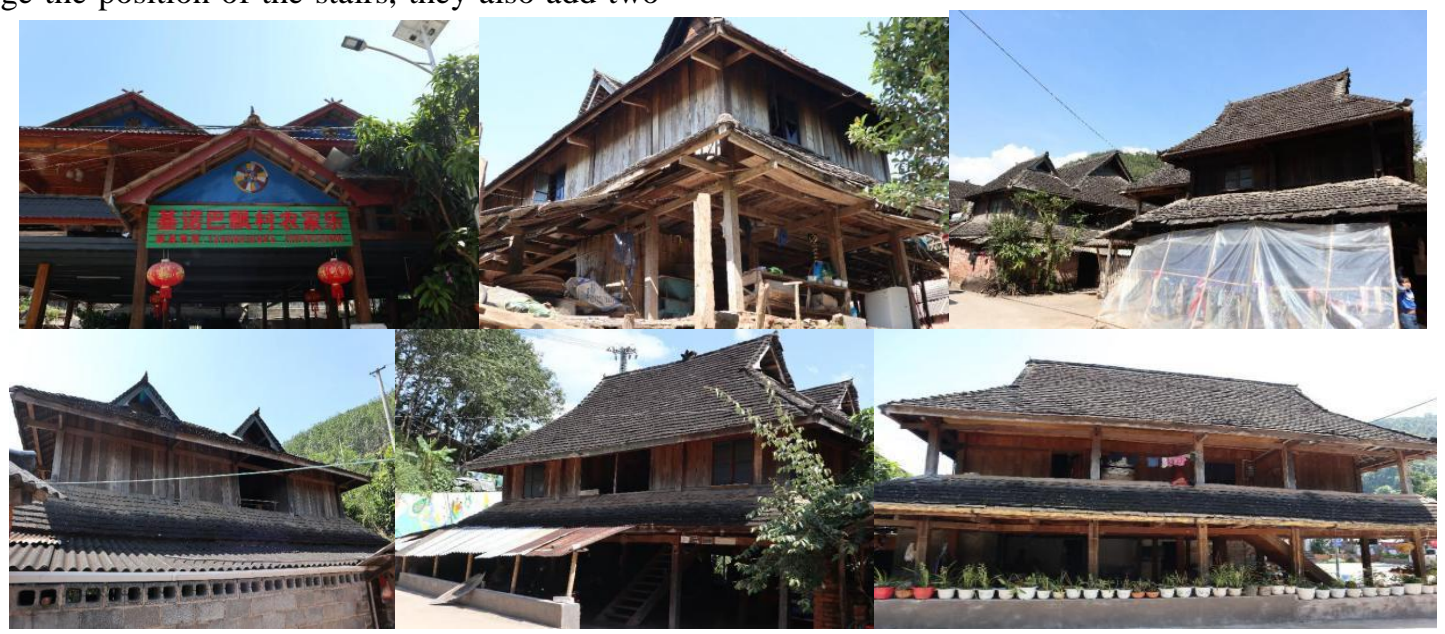

Figure 7 Some residential buildings in Ba Piao Village. (Self-photographed by the authors)

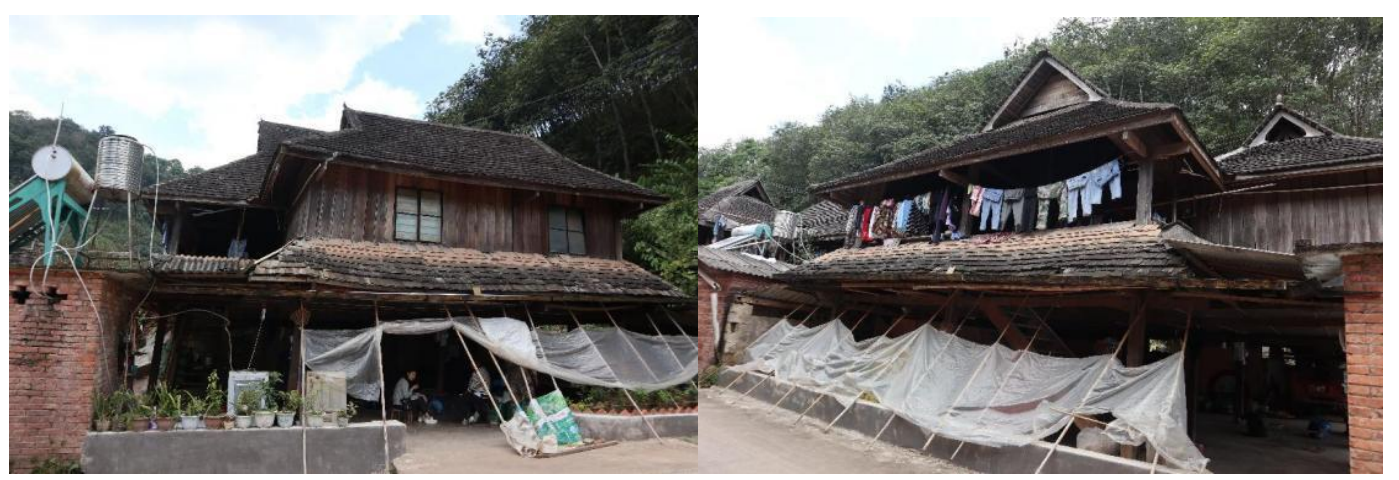

Figure 8 Zhuoba's Home in Ba Piao Village. (Self-photographed by the authors) 

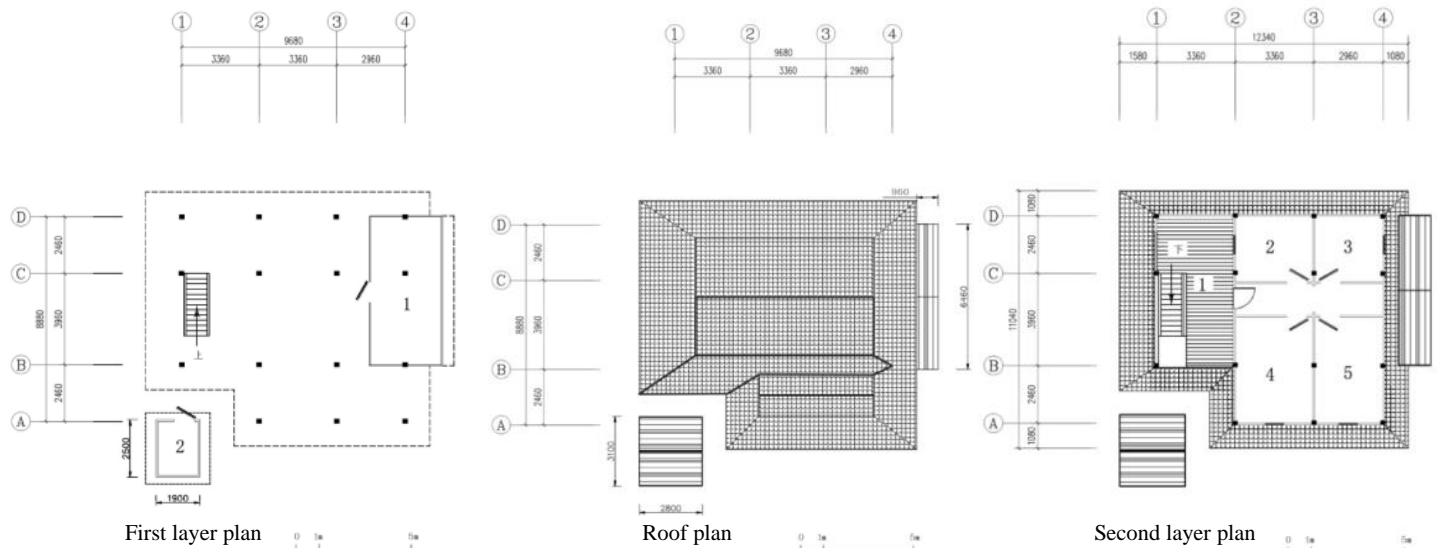

First layer plan Roof plan

Second layer plan
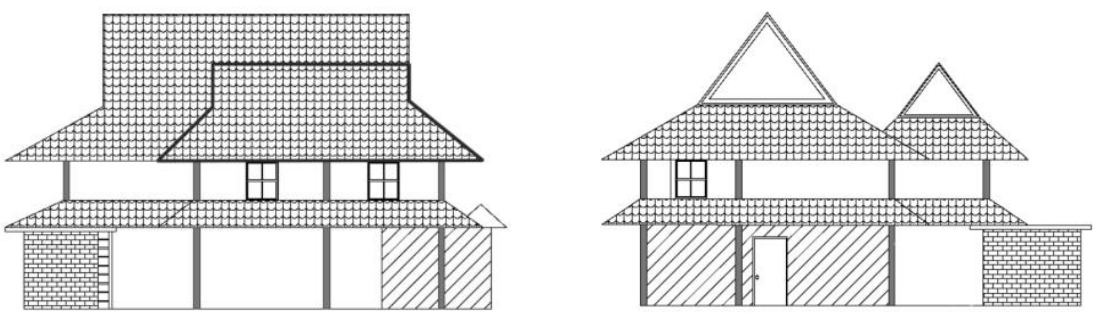

Southwest elevation

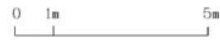

Northwest elevation $\quad 0$ im

Figure 9 Survey drawing of Zhuoba's home in Ba Piao Village. (Self-drawn by the authors)

a In the "First layer plan", 1-kitchen, 2-bathroom

\section{In the "Second layer plan, 1-hall, 2-drum god room, 3-storage room, 4-host's room, 5-children's room.}

\section{2000-2020: THE COLLISION OF TRADITION AND MODERNITY}

\subsection{The Impact of Color Steel Tiles}

Since 2008, color steel tiles have become popular all over the country due to their convenient construction, shelter from wind and rain, and low cost of building houses. In 2013, in Jinuo Township, except for villages like Ba Piao Village where the government forced to retain the original tile roofs, the rest were funded by the government and raised by the villagers for a total of about 4000 yuan. Color steel tiles can be used to renovate old roofs. Compared with the traditional construction methods of hundreds of thousands, the color steel tiles are sought after by the villagers. However, since 2017, the government has begun to regulate that villagers are not allowed to build color steel tile roofs privately. The first is that the self-built houses in the village are too random when installing color steel tiles, and they are prone to rust after prolonged exposure to the sun and rain. In particular, the joints and nail holes are not reliable, and they may be blown over in severe weather with strong winds and heavy rains, causing great safety hazards. The second is that the single-layer color steel plate has poor heat and sound insulation. It is installed on the roof. When it rains, there is no way to sleep in the house. There will even be a noise when a leaf falls on the tile. If the sun shines directly, the temperature of the room will rise quickly. The third is that the filling in the middle of the double-layer color steel tile is flammable and not easy to extinguish, and burning will produce toxic gas. In order to solve the problem of colored steel tile roofs in Jinuo Mountain, the government has conducted a pilot project in Baka Laozhai. Baka Laozhai is a typical government governance. At first glance, Baka Village has small blue tile roofs ("Figure $10 ")$. 


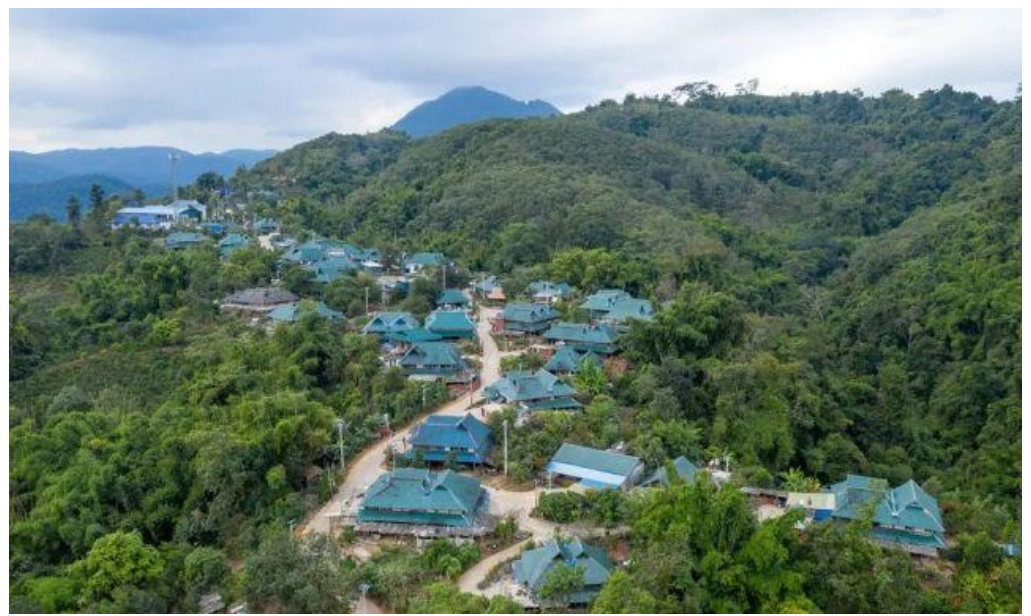

Figure 10

The regular Baka Laozhai.

\subsection{The Arrival of the Retro Wave}

Villagers who are forbidden to use asbestos tiles want to use the original filament tiles or small blue tiles, but find that it is becoming more and more difficult to buy, and the price has become unaffordable. At the same time, the acquisition of wood is also a problem. Cheap asbestos tiles are

Table 1. Combinations of various roofs and walls

\begin{tabular}{|c|c|c|c|}
\hline $\begin{array}{c}\text { Name of the } \\
\text { village }\end{array}$ & Icon & Form & Conclusion \\
\hline \multirow[t]{3}{*}{ Ba Piao Village } & & $\begin{array}{l}\text { Filament tile roofs and } \\
\text { brick-concrete } \\
\text { dwellings }\end{array}$ & $\begin{array}{l}\text { The entire stockade } \\
\text { forms a unified } \\
\text { architectural style with } \\
\text { filament tile roof as } \\
\text { the mainstay, and } \\
\text { many combinations } \\
\text { and changes have } \\
\text { been produced in it }\end{array}$ \\
\hline & & $\begin{array}{l}\text { Combination of Ffilament } \\
\text { tile roof and asbestos tile }\end{array}$ & \\
\hline & & $\begin{array}{l}\text { The combined use of } \\
\text { small blue tiles and color } \\
\text { steel tiles }\end{array}$ & $\begin{array}{l}\text { Baka Laozhai forms a } \\
\text { building group } \\
\text { dominated by small } \\
\text { blue tile roofs, and the } \\
\text { whole village appears } \\
\text { to be harmonious and } \\
\text { unified }\end{array}$ \\
\hline
\end{tabular}




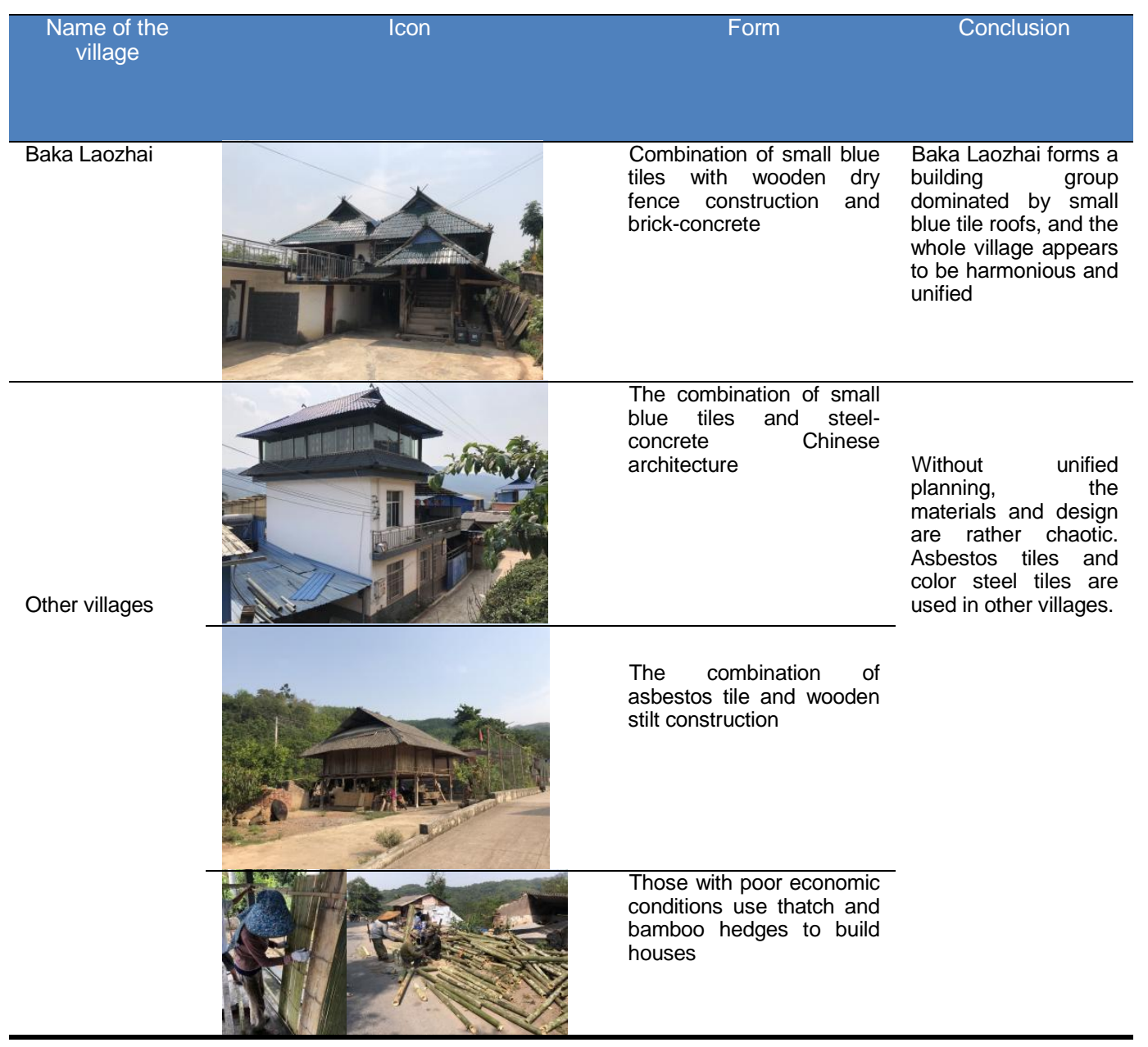

This table is made by the authors.

In June 2009, a series of activities of "30 years of Jinuo's leapfrog development" was held in the Great Hall of the People in Beijing. Jinuo Mountain has been listed by the National People's Commission as a pilot project for the comprehensive development of poverty alleviation for 22 ethnic minorities in the country. In the next few years, the government invested a large amount of funds for infrastructure construction. In the construction of private houses, in order to cooperate with tourism development, the restoration of the Jinuo landscape has become an important task. Ba Piao Village has become a pilot. In 2013, the renovation of the color steel tiles in Jinuoshan Township was in full swing, but the villagers of $\mathrm{Ba}$ Piao Village were not able to participate. The villagers were not happy at first. On the one hand, the original asbestos tiles have been banned, on the other hand, filament tiles need to be replaced and maintained frequently, which is far less convenient, affordable and durable than colored steel tile roofs and brick-concrete tiles. With the continuous mobilization and funding of the government, the villagers of Ba Piao Village gradually accepted the retro movement and reached an agreement to maintain a good village landscape ("Figure 11"). 


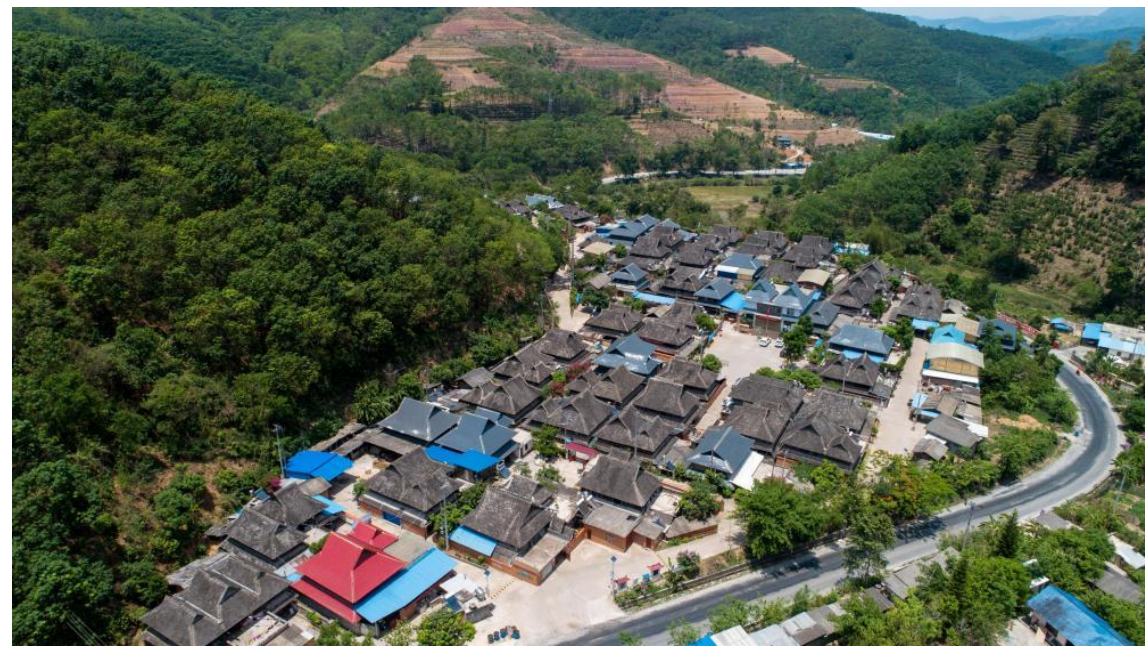

Figure 11 Bapiao Village, a characteristic village of Jinuo nationality.

\section{THE DEVELOPMENT AND PREDICAMENT OF THE JINUO DWELLINGS}

The Jinuo people transitioned directly from primitive society to the socialist society "straightthrough nation". Since the reform and opening up, the development of Jinuo Mountain has entered a rather typical "Jinuo Model". The communication channel between Jinuo Mountain and the outside world has been opened, and more and more people are going out to work. Most of the people who stay in the village are the elderly. If wooden buildings lack human maintenance, they will be more prone to damage and collapse.

The population and economy of Jinuo Mountain are developing rapidly, and many villages with original wooden structures are facing the development and construction of relocation to the new village, and the renovation and reconstruction of dwellings. The villagers lack the knowledge of cultural protection. Faced with the convenience of new materials and new buildings, they resist living in the old dwellings, and even discriminate against the villagers who continue to live in the old dwellings. As a result, Jinuo Mountain's new and old buildings are mixed with different architectural forms and lack of coordination, which destroys the cultural landscape of Jinuo Mountain. However, the villagers do not understand the policies formulated by the government to maintain the local traditional style. They need to renovate their houses to improve the quality of life. The government must actively publicize and make the villagers truly aware of the importance of residential protection.

For Jinuo Mountain, tourism can be said to be one of the local pillar industries. Tourism has promoted the development of the tertiary industry in Jinuo Mountain and increased the income of local villagers. The construction of tourist service facilities such as homestays, inns, and restaurants is bound to change the local architectural style of Jinuo Mountain, affect the production and lifestyle of the Jinuo people, and pose a huge challenge to the preservation and continuation of local material and intangible culture.

\section{CONCLUSION}

The changes in Jinuo's dwellings over the past 40 years are a microcosm of the changes in Jinuo's society. Many ethnic minority villages in Yunnan are going through the same course. When the traditional slow lifestyle collides with the fastpaced modern life, the traditional villages have many symptoms of discomfort. How to inherit and develop the wisdom of traditional houses? How to build new houses? How to let the locals "freely" continue to live on their land? This is an urgent problem to be solved.

It is an inevitable trend of historical development to adopt a large number of new crafts and new materials in the design of new dwellings, and how to localize is a thorny issue. If it is simply copied and bluntly combined with ethnic minority areas in Yunnan, especially the "straight-through nation" areas, it will have a negative impact. People 
can see from the case of Jinuo's dwellings' changes that the renewal and evolution of dwellings has its own special and spontaneous development and evolution logic. On the basis of fully understanding the local culture of the village, the designer should have "empathy" with the villagers, based on the principle of maintaining the "authenticity" of dwellings, and rationally use the unique structural forms and building materials of dwellings for design. The design of the dwellings is not to build a simple shelter, nor to build a tourist attraction, but to design the homes of the villagers. It should be to design a new dwelling that is more suitable for the local people's life, more reliable and safe.

\section{AUTHORS' CONTRIBUTIONS}

Weibing $\mathrm{Li}$ participated in the topic selection and determined the structure of the thesis, and revised the thesis; Qin $\mathrm{Li}$ made the research and thesis writing; and Jing Guo participated in the research and the writing of the paper.

\section{REFERENCES}

[1] Wu Yinghui, A Study of Contemporary Jinuo Society [M]. Kunming: Yunnan University Press, 2000. (in Chinese)

[2] Tian Yunxi. Study on landscape pattern characteristics of traditional villages in Jinuo Mountain in Jinghong Section of DianzanTibetan Tea-horse Ancient Road [D]. Southwest Forestry University, 2018. (in Chinese)

[3] Du Yuting, Exploration of a Harmonious but Different Chinese Ethnology: Du Yuting's Research Essays on the Jinuo Ethnic Group [M]. Yunnan: Yunnan University Press, 2009. (in Chinese)

[4] Revision and Editorial Committee of "Investigation Series on Social History of Chinese Ethnic Minorities", Dai Nationality Social History Survey (Xishuangbanna No. 1) [M]. Kunming, Yunnan Nationalities Publishing House, 1983: 46. (in Chinese)

[5] Zheng Xiaoyun, The Last Long House: The Patrilineal Family and Cultural Transformation of Jinuo People [M]. Kunming: Yunnan People's Publishing House, 2008: 20. (in Chinese)
[6] Wang Cuilan, Chen Moude, A Sequel to Yunnan Folk Houses [M]. Beijing: China Building Industry Press, 1993. (in Chinese)

[7] He Diandian, Luo Shaolin. Cultural performance and reproduction: anthropological interpretation of marriage and love culture of Jino people [J]. Journal of Sichuan Normal University (Social Science Edition), 2020, 47(03): 160-166. (in Chinese) 